\title{
Information accompaniment of the educational process of realization in the sustainable development interests at the University
}

\author{
Larisa Gagarina, Julia Shevnina* and Andrew Chirkov \\ National Research University of Electronic Technology, Institute for System and Software \\ Engineering and Information Technologies, 124498 Moscow, Zelenograd, Russia
}

\begin{abstract}
This article talks about the opportunity of possibly using a specialized automated system for information support of the implementation of the educational process in the interests of sustainable development at university. The usage of the system will allow to increase the educational efficiency of the specialists in the field of ecology, sociology and economics using integration and implementation of resources, experience and readymade sustainable development projects into the educational process by experts, teachers, partners and groups of scientists. Besides, the organization of interaction in the system between all project participants will help develop and strengthen horizontal links between them. The relevance of the implementation of the social component in such systems is shown.
\end{abstract}

\section{Introduction}

Education for Sustainable Development (ESD) is education which makes possible the social changes that are needed for making more socially fair communities and achieving sustainable development [1].

ESD consists of three parts-ecological, social, and economic, as well as aspects such as planning and developments of political decisions, finance, teaching, administration and etc. Sustainable development can't be achieved exclusively through technology, political regulation or financial mechanisms. Man kind has to change its way of thin king and behavior. To achieve this, high-quality education must be provided, as well as learning for sustainable development at all levels regardless of social conditions.

The educational process for sustainable developments hold in clued not only the study of its concepts and principles, but also the formation of systemic and critical thinking skills, allowing to consider environmental, social, economic and cultural aspects in total; establishing partnerships; decision making; understanding human rights and capabilities. The organization of such an educational process implies the integration and use of resources, experience and ready-made sustainable development projects from experts, teachers, partners and groups of scientists in training specialists. This will improve the quality and efficiency of training specialists in the field of sustainable development and is a particularly urgent task.

*Corresponding author: yusm@ rambler.ru 


\section{Information support system of the educational process in the interests of sustainable development}

\subsection{A system for organizing access to accumulated heterogeneous information resources}

To solve the above problems of ESD development and educational efficiency increase as well as the competence of the trained specialists, it is proposed to use a specialized automated information system for ESD support (hereinafter AIS ESD), based on the system of organizing access to the accumulated heterogeneous distributed information resources (IR) described in the described project [2]. The system consists of subsystems of the organization of profiled user interfaces; search in the IR collection; prompt delivery of information to the user; implementation of information security policy and requirements for delimiting access rights to IR and interface elements (fig. 1).

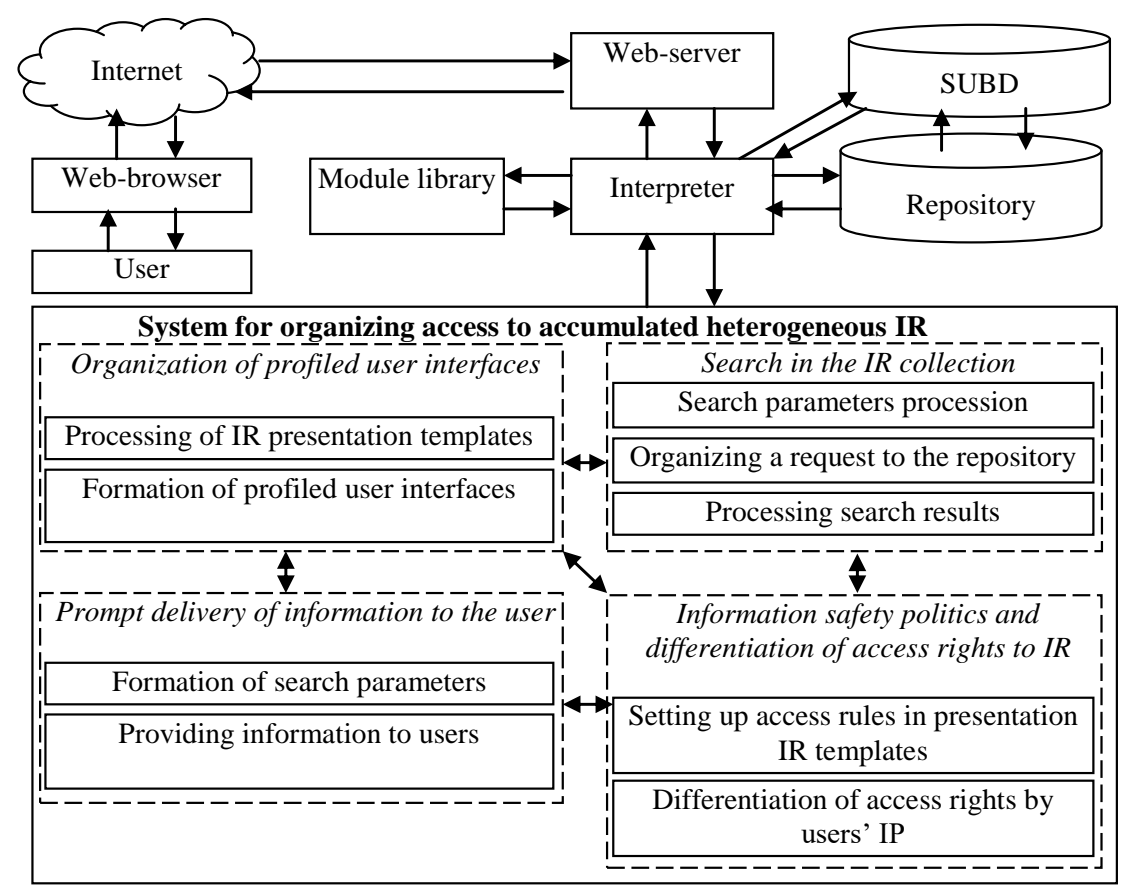

Fig. 1. General scheme of the system for organizing access to accumulated heterogeneous IR.

To implement AIS ESD in accordance with the methodology for using the access organization system, it is necessary to solve the following problems [3]:

1. Adaptation of the basic model of presentation of information resources to the terminology of the ESD project.

2. Providing delimited access for users to the corporate information resources accumulated during the implementation of the project, as well as to the services provided for working with the system.

3. Prompt informing of project participants about past and upcoming events. ESD.

4. Ensuring interaction of project participants with specialists and experts in the field of 


\subsection{Content presentation templates}

The result of the adaptation of the basic model of IR presentation to the terminology of the ESD project is a specialized IR presentation template:

$$
S=<T, R, D C, P, D_{1}, D_{2}, D_{3}, D_{4}>
$$

$T$ - the set of ESD project terms. $R$-the set of property values combined into a rubricates. $D C$-the set of metadata elements of the standard Dublin Core [6]. $P$ - the set of rules for accessing template elements (properties and their values). Elements of the $\mathrm{P}$ set are pairs $(k$, $f)$, where $k$ - is the role, $f$ - the level of access (access is opened, access is closed). $D_{1}-$ the $T \times R$ relation. $D_{2}-$ the $T$ x $D C$ relations. $D_{3}-$ the $T \times P$ relation. $D_{4}-$ the $R \times P$ relation.

Relations $D_{\mathrm{i}}$ have properties:

. $\forall t_{i} \in T \exists R_{i} \subset R: \forall r \in R_{i} \rightarrow\left(t_{i}, r\right) \in D_{1} \equiv t_{i} D_{1} r \wedge|R| \geq 1$.

- $\forall r \in R \exists ! t \in T: t D_{1} r$.

. $\forall t \in T \exists ! d c \in D C: t D_{2} d c$.

. $\forall t_{i} \in T \exists P_{i} \subset P: \forall p \in P_{i} \rightarrow\left(t_{i}, p\right) \in D_{3} \equiv t_{i} D_{3} p \wedge\left|P_{i}\right| \geq 0$.

- If $\left|P_{i}\right|=0$,then the element is available to all participants in the activity.

. $\exists p \in P \exists ! t \in T: t D_{3} p$.

• $\forall R_{j} \subset R: \forall r \in R_{j} \exists P_{j} \subset P: \forall p \in P_{j} \rightarrow\left(r_{j}, p\right) \in D_{4} \equiv r_{j} D_{4} p \wedge\left|P_{j}\right| \geq 0$.

• $\exists p \in P \exists ! r \in R: t D_{4} p$.

• $\exists t \in T \exists p \in P: \neg t D_{3} P \rightarrow \exists r \in R: r D_{4} p$.

- The same access rule cannot be simultaneously associated with a property and a property value.

The mathematical description of the derived template of the IR representation is obtained in a similar manner.

$$
S^{P}=<T^{P}, Z, R^{P}, D C, P^{P}, D_{1}^{P}, D_{2}^{P}, D_{3}^{P}, D_{4}^{P}, D_{5}>
$$

$T^{P}$ - the set of properties for IR description. $T^{P} \subset T . Z$-the set of meanings renaming the elements of the base template to represent them in a derivative. $R^{P}$ - multiple property values $T^{P}$ (rubricators). $R^{P} \subset R . D C$-the set of items from the DC metadata set. $P^{P}$ - the set of the access rules descriptions. The set of $P^{P}$ elements are in the form of pairs $(k, f)$, where $k$ - is the role, $f$ - the level of access (access is open, access is closed). ${ }^{D_{1}^{P}}$-the $T^{P} \mathrm{x}$ $R^{P}$ relation. $D_{2}^{P}$-the $T^{P} \times D C$ relation. ${ }^{D_{3}^{P}}$-the $T^{P} \times P^{P}$ relation, ${ }_{4}^{P}$-relation $R^{P} \times P^{P} . D_{5}-$ the $T^{P} \mathrm{x} Z$ relation.

Derived template relationship properties:

- $D_{1}^{P} \subset D_{1}$. $D_{1}^{P}$ is a set of ordered pairs $\left(t^{P}, r^{P}\right)$, and $D_{1}-(t, r)$. As $T^{P} \subset T$ and $R^{P} \subset R$, it follows $\forall t^{P} \in T^{P} \rightarrow t^{P} \in T$. Besides, corresponding properties $t^{P}$ and tare 
equial. Carrying out similar reasoning about the sets $R^{P}$ and $R$, we obtain that the corresponding pairs $\left(t^{P}, r^{P}\right)_{И}(t, r)_{\text {are equal, and it means }} D_{1}^{P} \subset D_{1}$.

- $D_{2}^{P} \subset D_{2}$. According to the information above, $T^{P} \subset T$. With this in mind, as well as the fact that when a derived template is obtained from the base DC, the interpretation of the element does not change, which means that the ordered pairs $\left(t^{P}, d c\right)$ and $(t, d c)$, corresponding to the properties $D_{2}^{P}$ and $D_{2}$ are equal, hence $D_{2}^{P} \subset D_{2}$.

- As $D_{1}^{P} \subset D_{1}$ and $D_{2}^{P} \subset D_{2}$, the $D_{1}^{P}$ and $D_{2}^{P}$ relations have the same properties as the $D_{1}$ and $D_{2}$ relation.

- The $D_{3}^{P}$ and $D_{4}^{P}$ properties are similar to the D3 and D4 properties: algebraic system S (1). And the $P^{P}$ properties are similar to the properties $P$ from $S$ (1).

- $\exists t^{P} \in T^{P} \exists z \subset Z: t^{P} D_{5} z$.

- $\exists t^{P} \in T^{P} \exists ! z \in Z: t^{P} D_{5} z$.

Mathematical description of the delivery template of the IR representation:

$$
S^{D}=<D C, G, I P, C, D_{6}>
$$

$D C_{-}$is the set of the elements from the Dublin Core standard. $G_{-}$is the set of multiple search parameter values. $I P-$ is the set of IP-addresses, from which access to the delivery user interface is allowed. $C_{-}$preferences (color, style). $D_{6}$ is the relation $D C \times G$, where $\forall g \in G \exists ! d c \in D C: d c D_{6} g$.

The IR description card model is an algebraic system.

$$
S^{K}=<D C, V, R, D_{7}, D_{8}>
$$

$D C_{-}$is the set of the elements from Dublin Core standard. $V$ - the set of values of description elements specified by the user. $R-$ is the set of the values of the description elements selected from the proposed rubricators. $D_{7}$ the $D C \times V$ relation. $D_{8}$-the $D C \times R$ relation.

The elements of algebraic system $S^{K}$ has the following properties:

- $\forall v \in V \exists ! d c \in D C: d c D_{7} v$.

- $\forall v \in V \forall d c \in D C:(d c, v) \notin D_{7} \rightarrow \forall r \in R \exists ! d c \in D C: d c D_{8} r$.

All the algebraic systems have a set. Taking into account the properties of the obtained algebraic systems, it follows that all types of IR representation templates and the IR description card are interconnected using elements of the DC standard. When forming specialized templates obtained as a result of setting up the basic model of the IR representation, all the necessary information is taken into account to build a profiled user interface. As are salt, each of the participants of the activity in its individual profiled interface receives the minimum set of interface elements necessary for it to work (for example, search for IR), displayed in the terminology of this line of activity. 
As a result of the adaptation of the basic model of presentation of IR, a specialized and a number of delivery ones were obtained. The templates were obtained using the results of ontological analysis [4]. A specialized template for the presentation of IRs used in an ESD project is described in Table 1.

Table 1. Description of the specialized IR presentation template.

\begin{tabular}{|c|c|c|}
\hline $\begin{array}{c}\text { Template element name (DC } \\
\text { name) }\end{array}$ & $\begin{array}{l}\text { Type of the } \\
\text { element }\end{array}$ & Meaning of the rubricator \\
\hline Type of resource & Rubricator & $\begin{array}{l}\text { Request } \\
\text { Contract } \\
\text { Attachments to the contract } \\
\text { Activity report } \\
\text { Professional development report } \\
\text { Report Form } \\
\text { Purchase } \\
\text { Scheduled tasks } \\
\text { ERW (educational and research work) } \\
\text { Order } \\
\text { Position } \\
\text { Service letter } \\
\text { Memo } \\
\text { Plan } \\
\text { Presentation } \\
\text { Working materials } \\
\text { Requirements for materials } \\
\text { Regulations } \\
\text { Personalities } \\
\text { Scheme } \\
\text { Order }\end{array}$ \\
\hline Audience & Rubricator & $\begin{array}{l}\text { For the project management } \\
\text { For the project coordinating council } \\
\text { For program participants }\end{array}$ \\
\hline Subject of the education & Rubricator & $\begin{array}{l}\text { Ecology } \\
\text { Economics } \\
\text { Sociology }\end{array}$ \\
\hline Creator (responsible performer) & Rubricator & All project managers by area \\
\hline Document category (rights) & Rubricator & $\begin{array}{l}\text { Internal } \\
\text { External }\end{array}$ \\
\hline Coverage & Rubricator & $\begin{array}{l}\text { Forced mailing } \\
\text { Information material }\end{array}$ \\
\hline Title & Text & - \\
\hline Relation & Text & - \\
\hline Date of approval (created) & Date & - \\
\hline Identifier & Text & - \\
\hline Format of the resource & Rubricator & $\begin{array}{l}\text { ZIP archive } \\
\text { RAR Archive } \\
\text { Audio Video } \\
\text { Word document } \\
\text { PDF document } \\
\text { Picture } \\
\text { Materials on electronic media } \\
\text { Printed editions } \\
\text { PowerPoint presentation } \\
\text { Program } \\
\text { Mixed }\end{array}$ \\
\hline
\end{tabular}




\begin{tabular}{|l|l|l|}
\hline & & Text \\
& & HTML text \\
\hline Note (abstract) & Text & - \\
\hline
\end{tabular}

Based on the results of the ontological analysis, the roles of users participating in the implementation of the ESD project were formed: project participant, member of the project directorate, member of the project coordinating council, project manager, partner, student.

Based on the developed templates for the presentation of IR, profiled user interfaces were obtained: search and delivery.

A mechanism for the exchange of information resources between all project participants is described on the basis of a previously created work plan.

An approach is described that provides the user with the necessary set of services and profiled interfaces without additional identification and authorization.

\subsection{Information- Guidance Portal for Project ESD Realization}

Access to AIS ESD is carried out through the Information Support Portal for the implementation of the ESD project, which is divided into two areas: external and internal (fig. 2).

The outer area is the same for all users who log into the portal. Here you can find external IRs on the ESD project, external reports on the progress of the project implementation, information on the implementation and monitoring of the project, as well as information on upcoming and past events.

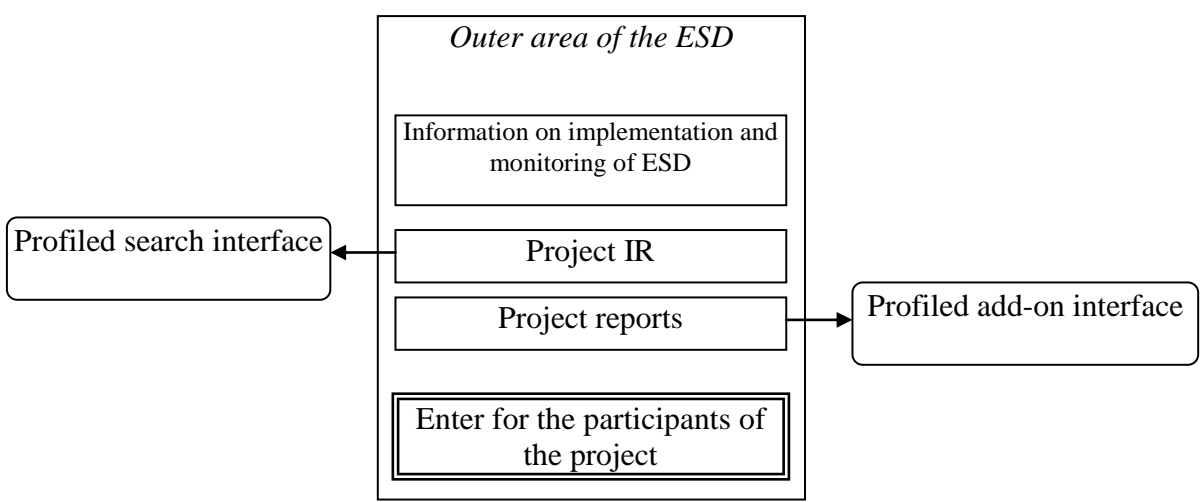

Fig. 2. Scheme of the external area of the portal for information support of the ESD project implementation

To access the IR for the project, a profiled search interface is used, built on the basis of a derived IR representation template. A derived template consists of the elements: Type, Audience, Document Category, Manager (Executive), Title. Moreover, the rubrics "Type" and "Manager (responsible executor)" contain only those values for which there are resources in the system (fig. 3). The values of the rubrics "Audience" and "Document Category" are set by default, "For all" and "External", respectively, and these rubrics are not present in the profiled search user interface. 


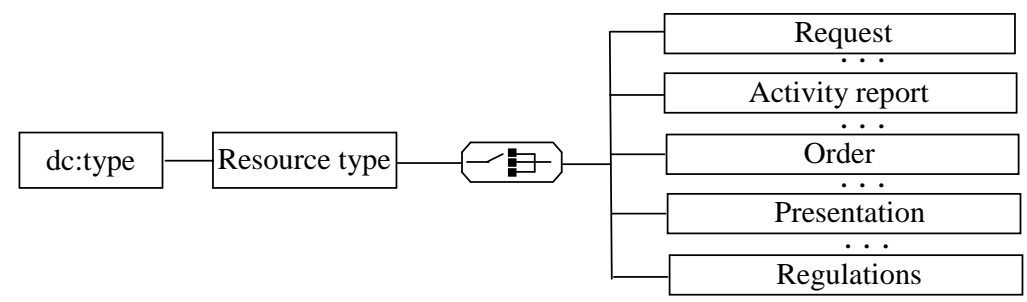

Fig. 3. Rubricator "Type of resource" for the profiled search interface "Information resources for the project"

An example of building an interface element "Resource type" is described in table 2.

Table 2."Resource type" element of the IR representation template

\begin{tabular}{|c|c|c|}
\hline T, DC & & $\mathbf{R}$ \\
\hline $\begin{array}{c}\text { Resource type } \\
t_{1}, d c 8\end{array}$ & Rubricator & $\begin{array}{l}r_{1}-\text { Request } \\
r_{2}-\text { Agreement } \\
r_{3}-\text { Attachments to the contract } \\
r_{4} \text {-Activity report } \\
r_{5}-\text { Training report } \\
r_{6}-\text { Reports' form } \\
r_{7}-\text { Purchase } \\
r_{8}-\text { Assigned tasks } \\
r_{9}-\text { ERW (educational and research work) } \\
r_{10} \text { - Order } \\
r_{11} \text { - Provision } \\
r_{12}-\text { Service letter } \\
r_{13} \text { - Memo } \\
r_{14} \text { - Plan } \\
r_{15} \text { - Presentation } \\
r_{16}-\text { Working materials } \\
r_{17}-\text { Material requirements } \\
r_{18} \text { - Requirements } \\
r_{19} \text { - Personalities } \\
r_{20} \text { - Scheme } \\
r_{21} \text { - Disposition }\end{array}$ \\
\hline
\end{tabular}

Algebraic system $S^{P}$ for this template element presentation of IR will have the form $S^{P}=<\left\{t_{1}\right\},\left\{r_{1}-r_{21}\right\},\left\{d c_{8}\right\},\left\{t_{1},\left\{r_{1}-r_{21}\right\}\right\},\left\{t_{1}, d c_{8}\right\}>$. According to the method presented in [1] for constructing profiled user interfaces, we will select an event that will become the root of the tree. Thehandler $d c_{8}$ willbecomethisevent.Further, in accordance with the algorithm, for each vertex of the tree $s \in L_{n-1}: M_{1} s \neq \varnothing_{\text {we need to add the sequence elements }} M_{1} s$.

$$
M_{1} d c_{8}=\left\{t_{1}\right\}, M_{1} t_{1}=\left\{R_{1}\right\}, M_{1} R_{1}=\varnothing .
$$

The constructed element "Resource type" of the profiled search interface is presented on the fig.3.

For quick access to external reports on the program, a profiled delivery interface is used, formed on the basis of the developed delivery template for the presentation of IR. The following parameters were set as the values of the elements of this delivery template: "Resource type" - "Event reports", "Document category" - "External".

The inner part of the portal is available only for project participants. To go to the inner part of the portal for information support for the implementation of ESD, project participants must be identified by the IP addresses of their working personal computers. If the computer's IP address for some reason could not be determined or the IP address is not registered in the 
system, then the project implementation participant is asked to enter a username and password to access the internal part of the ESD portal for subsequent identification and authorization on the portal. In addition to external information resources, internal IRs are also available on the inner part of the ESD portal (fig. 4): working materials, orders, presentations, reports, as well as information on internal upcoming and past events.

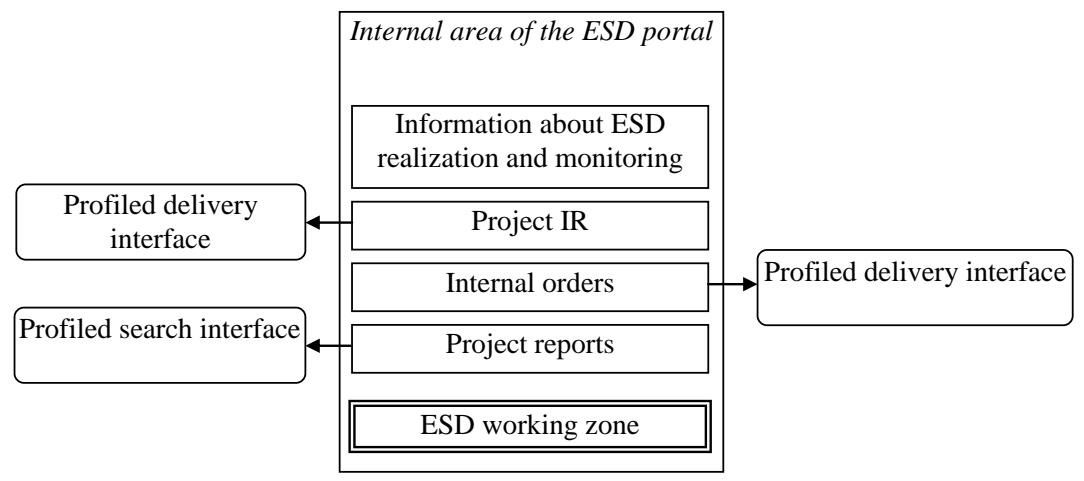

Fig. 4. Structural diagram of the internal area of the ESD portal

To access the IR from the internal area of the portal for information support of the ESD project implementation, a profiled search interface is used, built on the basis of a derived IR representation template. The profiled interface contains the following elements: "Type", "Audience", "Manager (responsible executive)", "Title". The "Document category" element, despite the fact that it is present in the IR presentation template, is not displayed in the interface, since it has only one default value - "Internal". The "Type" rubricator contains only those values that correspond to the descriptions of the IR accumulated in the system. Access to internal orders for the ESD project is based on a profiled delivery user interface. The delivery template used in the formation of this profiled interface contains the search parameters: "Resource type" - "Order", "Document category" - "Internal".

Project reports are available to ESD project participants through a profiled search interface. This interface includes the following elements: "Audience", "Leader (responsible executive)", "Direction of training" and "Title". The Resource Type and Document Category items are not displayed in the user interface, but have default values of Event Reports and Internal.

In the inner area of the ESD project portal there is an entrance to the ESD working area, which is divided into a training block, a Competence Center (CTF), ESD management and a scientific block (fig. 5).

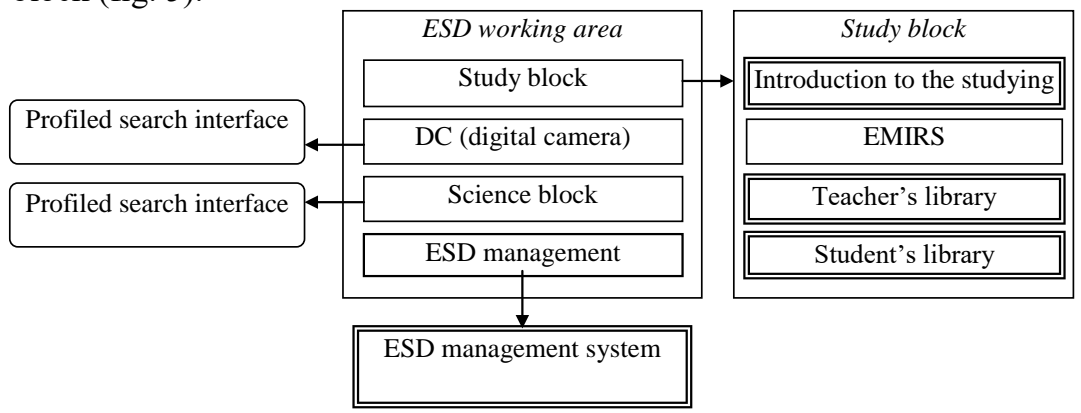

Fig. 5. Structural diagram of the ESD working area. 
For access to the IR of the sections "CFC" and "Scientific block", profiled search interfaces are connected, built taking into account all the needs of end users of these sections.

\subsection{Educational block of information support system for ESD project implementation}

"Educational block" consists of "Implementation in the educational process", "EMIRS", "Teacher's library", "Student's library". "Implementation in the educational process" is an entry into the system of support for the learning process. Each department of the university in this system is allocated its own workspace, consisting of an educational area and a library (fig. 6). The study area includes the functionality for working with the curriculum, electronic modules for individual student work (EMIRS), sending / receiving homework by students and teachers, etc.

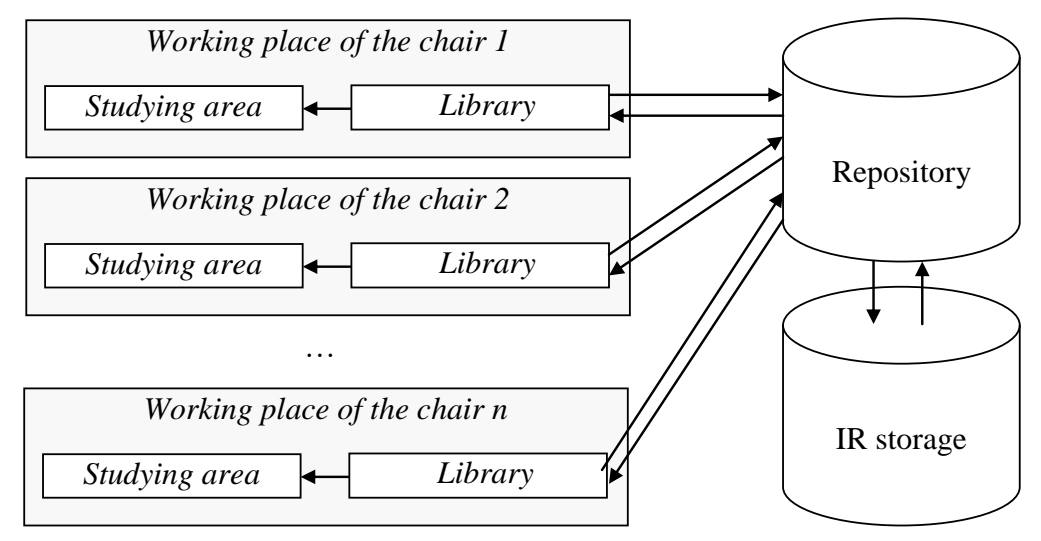

Fig. 6. Scheme of the organization of the working space of the department

Sending and receiving homework by students and teachers is implemented through special profiled interfaces [5]. The profiled student interface for submitting homework consists of the elements "Discipline name", "Lesson name", "Job type", "Teacher". A rubricator is connected to each of these elements. Moreover, the rubrics "Discipline name", "Lesson name" and "Teacher" are formed in accordance with the curriculum, which is created in advance. Thus, each student in his profiled interface receives only those values of disciplines and classes for which he is currently scheduled to send the results of independent work for verification.

The profiled interface for submitting checked homework by the teacher consists of the elements "Discipline name", "Lesson name", "Group", "Student", "General instructions", "Recommendations for correcting errors", "Assessment". Similar to the profiled student interface, rubricators are connected to each of these elements. Moreover, the values of the rubricators "Discipline Name" and "Lesson Name" consist only of those names of disciplines in which the teacher conducts classes at the current moment. And the rubricators "Group" and "Student" are only from those students with whom the teacher is working at the moment.

The use of rubricators in such profiled interfaces allows not only to reduce the time of sending and receiving homework, but also avoids many mistakes. Since the user does not need to enter data, but is asked to choose from the existing ones.

In the profiled interface of the teacher for receiving completed homework, the function "Quick access to unverified work" has been added. This function allows you to receive unverified papers in all disciplines and all students, addressed to this teacher. The need for such a function was revealed as a result of ontological analysis of real practical activities of 
obtaining a student's test by a teacher. This function made it possible to significantly reduce the time spent by the teacher to work in the system when receiving term papers for verification. Having carried out statistical studies of the teacher's actions to receive completed homework, it was found that the teacher makes 10 clicks (clicks) of the mouse on average to get one homework of one student. This is the selection of the menu item "Receiving the DR", the selection of the values of the rubrics "Discipline name", "Lesson name", "Type of work", "Group", "Student" opening. Using the button "Quick access to unverified works" for the same operation, the teacher makes 5 clicks: select the menu item "Receive DR", press the button "Quick access to unverified works", select a work, view its description and open. Obviously, getting one homework using the "Quick access to unverified works" function is 2 times faster. Also, a statistical study was carried out on the receipt by one teacher of $n$ works in d disciplines, $z$ classes, $k$ students from $g$ groups and on $v$ types of work. Let $t$ be the time of one mouse click. Taking into account that the values of all rubrics depend on the value of the rubricator "Discipline name", and the values of the rubricator "Student" also depend on the selected value in the rubricator "Group", we get the following time $T 1$ for checking works.

$$
T_{1}=d z v g k t+d(t+z(t+v(t+g(t+k(t+t)))))+n(t+t+t)
$$

To perform the same operation, but using the function of quick access to unverified works, it took the teachers $T_{2}$ time. During the study, the dependence of the search time for jobs with a single search query on the number of jobs found was revealed. After analyzing the statistical data of the server: the number of user requests, the processing time of requests, etc., a correction coefficient was obtained for the dependence of the search time on the number of jobs, i.e. search time for test papers is increased by $1.46 n$, where $\mathrm{n}$ is the number of jobs found.

$$
T_{2}=t+t+n(t+t+t)+1,46 n t
$$

To obtain a quantitative value of the ratio $/ T_{2}$, the average values of the coefficients included in the formulas are determined.

$$
\begin{aligned}
& d=4, z=2, v=1, g=3, k=60, r=200 . \\
& T_{1}=4964 t, T_{2}=1496 t, T_{1} / T_{2}=3,3 . \text { Thus, the use }
\end{aligned}
$$

structure of which is adapted to ESD, made it possible to reduce by 3.3 times the time spent by a teacher to receive tests for verification.

Working with the library, you can load IRs, search for them, view meta descriptions, etc. Information resources uploaded to the library can be connected to the curriculum and used as the main or additional material in the study of the discipline by the student. All information resources accumulated by the departments in the course of their work are placed in a single information storage (fig. 6). But, despite this, the staff of each department will have access only to "their" resources. This effect is achieved by setting rights to elements of the IR presentation template and organizing personal profiled user interfaces for each employee of the department. For quick access to information resources of the library, both for teachers and students, the inputs on the page of the educational block "Teacher's Library" and "Student's Library" are used, respectively (fig. 5).

When working with the library, profiled user interfaces are widely used. These interfaces are built on the basis of a basic template for the presentation of educational IR, developed on the basis of an ontological analysis of the educational subject activity of the university. For example, for the rubricator "Type of resource" (DC element - "type"), only those values were 
chosen that are used in the real educational process and the corresponding electronic versions are present in the library (fig. 7 a). The rubric "Audience" (DC element - "audience") (fig. 7 b), which is used to determine the target audience for the purpose of the IR, is very important.

a)
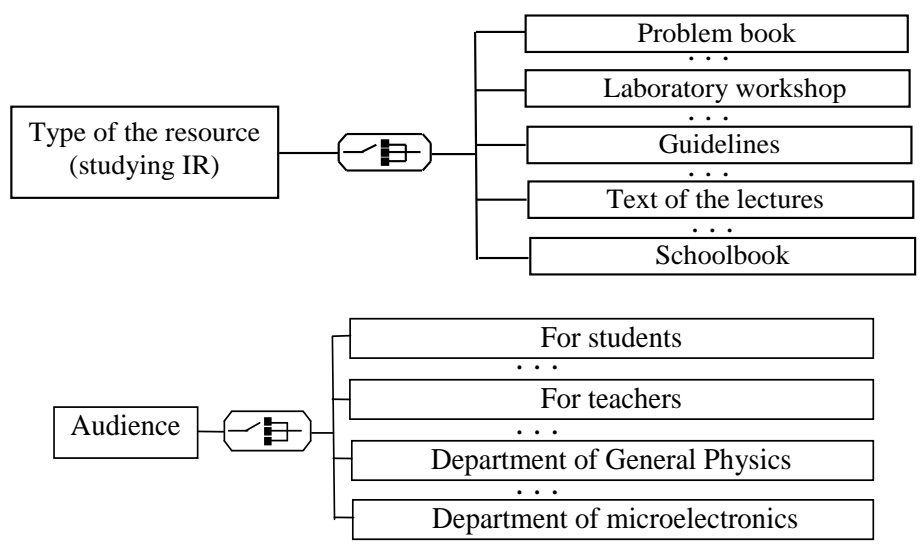

b)

Fig. 7. Rubricators of the basic template for the presentation of educational IR.

Delivery profiled interface is connected to the section of the educational block "EMIRS" for quick and convenient access for teachers and methodologists of departments to organizational and administrative documents for the creation and use of electronic modules for individual work of students, as well as examples of the modules themselves.

\subsection{ESD project management}

The "ESD Management" section of the workspace is an entrance to the information system for supporting and managing the implementation of an ESD project. As a result of the ontological study of education for sustainable development, carried out on the basis of an analysis of various organizational and administrative documents for the project, the following roles and user groups were identified:

- Project's directorate.

- Managers (responsible executors) of the main tasks of the project.

- Leaders (responsible executors) of the directions (activities) identified within the framework of the main tasks of the project.

- Participants of the project (subsections).

In the information system for support and management of the implementation of the ESD project, user interaction is organized (or the exchange of information resources within the system) (fig. 8):

- Users of the "Project Coordinating Council" group within the system can interact with each other, as well as with members of the project management.

- Members of the project directorate exchange resources among themselves, as well as with the project coordinating council and the leaders of the main tasks.

- The leaders of the main tasks interact with each other, as well as with the members of the project directorate and the leaders of the directions in their task.

- Heads of directions for each of the tasks, in addition to the exchange of resources with the heads of the main tasks, can exchange resources with the project participants (department employees).

- Project participants transfer and receive resources from the employees of their unit and from the leaders of their direction. 
In addition to the exchange of information, administrative and working $\mathrm{R} \& \mathrm{D}$, the system also implies the exchange of work results. The exchange of results of work is based on the tasks of the ESD implementation plan in the direction. Such a plan is assigned to a group of project participants (department) and, according to the tasks (reporting activities) prescribed in it, the project participant transfers his work result to his manager, which the manager can accept or reject.

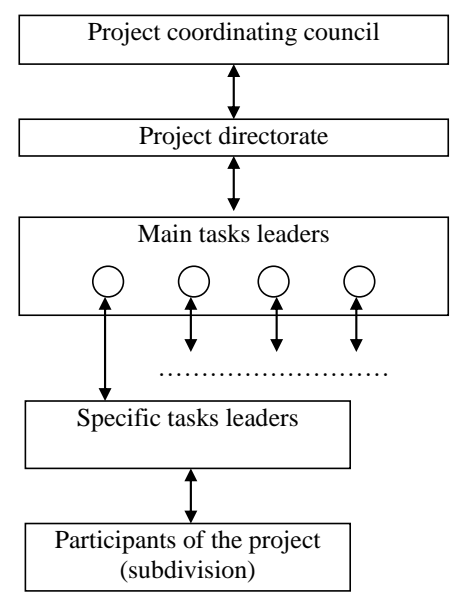

Fig. 8.Users' interaction with in the ESD management system

Each of the participants in the implementation of the ESD project within the framework of the project management system received its own profiled interface both for downloading / searching for organizational and administrative and working IRs, and for sending / receiving the results of the work done. The profiling of the user interface consists in restricting access to the elements of the rubrics: "Manager (responsible executive)", "Type", "Audience", "Document category", "Status". Access restriction is made based on the analysis of specific tasks and directions of the project participant.

\section{Results}

The use of the specialized automated system developed and described in this work for information support of education in the interests of sustainable development at the university made it possible to significantly simplify the access of the project participants to the information resources accumulated during the implementation of the IR, as well as to the services provided for working with the system. Thanks to the adaptation of the interface elements and meta-descriptions of the IR to the terminology of the ESD project, as well as the narrowing of information flows coming to the project participants, it was possible to increase the efficiency of their work with the resources it needs. As part of the ESD management system, a simple and convenient scheme for the exchange of information resources between all project participants has been implemented, thanks to the use of profiled user interfaces. Profiled user interfaces also made it possible for task and direction managers to quickly and efficiently receive the results of the work done in the form of reports from project participants.

\section{Discussion}


The current global situation with coronavirus is pushing for remote interaction of participants in the educational process. This must be taken into account when developing an information system to support the implementation of the educational process in the interests of sustainable development. It is worth providing for a separate functional block that has the basic capabilities of a social network: the exchange of personal messages, the creation of communities, the organization of discussions and conferences. This will create conditions for the communication of participants in the educational process in a single environment. Since the use of various messengers, online communication tools, social networks and e-mail requires additional efforts to structure, classify and process incoming information.

\section{Conclusion}

The use of a specialized automated system for information support of the implementation of the educational process in the interests of sustainable development at the university will increase the efficiency of training specialists in the field of ecology, sociology and economics by integrating and introducing resources, experience and ready-made sustainable development projects on the part of experts, teachers, into the educational process, partners and groups of scientists. In addition, the organization of interaction in the system between all project participants will develop and strengthen horizontal links between them.

\section{References}

1. Education for Sustainable Development, https://en.unesco.org/themes/educationsustainable-development/

2. Ju.S. Shevnina, Science and education, 1, 0420700025 (2010).

3. Ju.S. Shevnina, Actual innovative research: science and practice, 1. 2075-9843, (2010).

4. Yu.S Shevnina, N.Yu.Sokolova, Z. Ye. Kyaw, EIConRus, 2076 (2021).

5. A. Tsirlin, L. Gagarina, 22(8), 891 (2020).

6. DCMI Metadata Terms, http://dublincore.org/documents/dcmi-terms/

7. R.L. Akof, M. Sasiyeni, Osnovy issledovaniya operatsiy (Mir, 1971)

8. A.A. Bogdanov, Tektologiya: Vseobshchaya organizatsionnaya nauka, (Finansy, 2003)

9. A. I. Uyomov, L. fon Bertalanfi, Sistemnyy podkhod v sovremennoy nauke, 37 (2004)

10. A.N. Khoroshev, Vvedeniye v upravleniye proyektirovaniyem mekhanicheskikh system, (Belgorod, 1999)

11. A.A. Samarskiy, A.A. Matematicheskiye modeli. Idei. Metody. Primery (Fizmatlit, 2002) 